\title{
Subsurface Geology of Pantar Island Geothermal System-East Nusa Tenggara, Indonesia, Based on Rock Resistivity Analysis
}

\author{
Yoqi Ali Taufan", Ildrem Syafri' ${ }^{2}$, Andi Agus Nur ${ }^{2}$
}

\author{
Dikdik Risdianto ${ }^{3}$ \\ Padjadjaran University, Faculty of Geological Engineering, Master Program, Indonesia ${ }^{1}$ \\ Padjadjaran University, Faculty of Geological Engineering, Indonesia ${ }^{2}$ \\ Centre for Minerals, Coal, and Geothermal Resources, Geothermal Group, Bandung, Indonesia
}

\section{E-mail: yoqie.taufan@gmail.com ${ }^{1}$, ildrem@unpad.ac.id ${ }^{2}$ DOI< 10.26821/IJSHRE.8.5.2020.8506>}

\begin{abstract}
The existence of geothermal potential must meet the criteria of the subsurface geological conditions of a geothermal system. Limitations on depth penetration generated by gravity and AMT (Audio-frequency Magnetotellurics) methods that have been carried out to search for geothermal potential on Pantar Island, are overcome by geophysical investigations of Magnetotellurics (MT) method in order to gain deeper penetration. In principle, differences in rock resistivity in the geothermal system provides subsurface geological information in the form of low resistivity that reflects the conductive layer (high conductive) associated with the clay cap zone, the medium resistivity zone associated with the reservoir zone, and high resistivity which reflects rocks with a heat source. The results of $2 D$ and $3 D$ models of MT data show the existence of low resistivity distribution $(<20 \Omega \mathrm{m})$ in almost all areas of investigation, this low value is thought to be a response from alteration, tuff, breccia, polymic breccia, and pyroclastic in the west to parts middle, while the low resistivity value in the east is thought to be the presence of sea water intrusion. Medium resistivity values (20-100 $\Omega$ m) appear below the low resistivity values around the existence of geothermal manifestations, which describe the existence of reservoirs starting at depths of -1000 meters, while rocks with high resistivity values $>200$ $\Omega m$ are thought to be heat-bearing rocks from the geothermal system Pantar starts at a depth of -2000 meters.
\end{abstract}

Yoqi Ali Taufan, Ildrem Syafri, Andi Agus Nur, Dikdik Risdianto', Vol 8 Issue 5, pp 7-15, May 2020
Keywords: Magnetotellurics, resistivity, geothermal

\section{INTRODUCTION}

Utilization of geothermal energy depend on the exploration effort to find for potential energy sources. Locations with geological conditions that have criteria from geothermal systems are needed. The system is indicated by the presence of clay cap layers from geothermal reservoir rocks, geological structures that are generally in the form of faults, reservoir rocks where fluids accumulate, heat sources, and fluids. The existence of a geothermal system in an area will not exist if the components of the geothermal system are not met (D.H. Carlson, 2008), (I.S. Moeck, 2014)

Geophysical investigation with gravity method and AMT (Audio Magnetotellurics) method for geothermal potential on Pantar Island was conducted in 2015. This investigation was aimed at finding out the geothermal system on Pantar Island (Figure 1). The results of the investigation with 2 (two) methods are still limited to the depth of subsurface geological information (T. Rahadinata, 2015).

Geophysical investigation using Magnetotellurics (MT) method was carried out as a follow-up, this method has the advantage of deeper penetration with better accuracy compared to previous investigations.

The difference in rock resistivity in geothermal systems results in horizontal and vertical rock resistivity maps that can provide subsurface geological 
Volume 8 Issue 5 May 2020

information in the study area, in the form of low resistivity that reflects the conductive layer (high conductive), medium resistivity as a reservoir zone, and high resistivity (high resistivity) which reflects rocks with a heat source (heat source) below the surface. (S. Panjaitan, 2010).
The purpose of this research is to study the geology of the subsurface geothermal system in the Pantar Island region, and obtain 2D \& 3D subsurface models in the Pantar Island geothermal region based on the resistivity parameters generated from Magnetotellurics (MT) which is continuation of the method from previous studies.

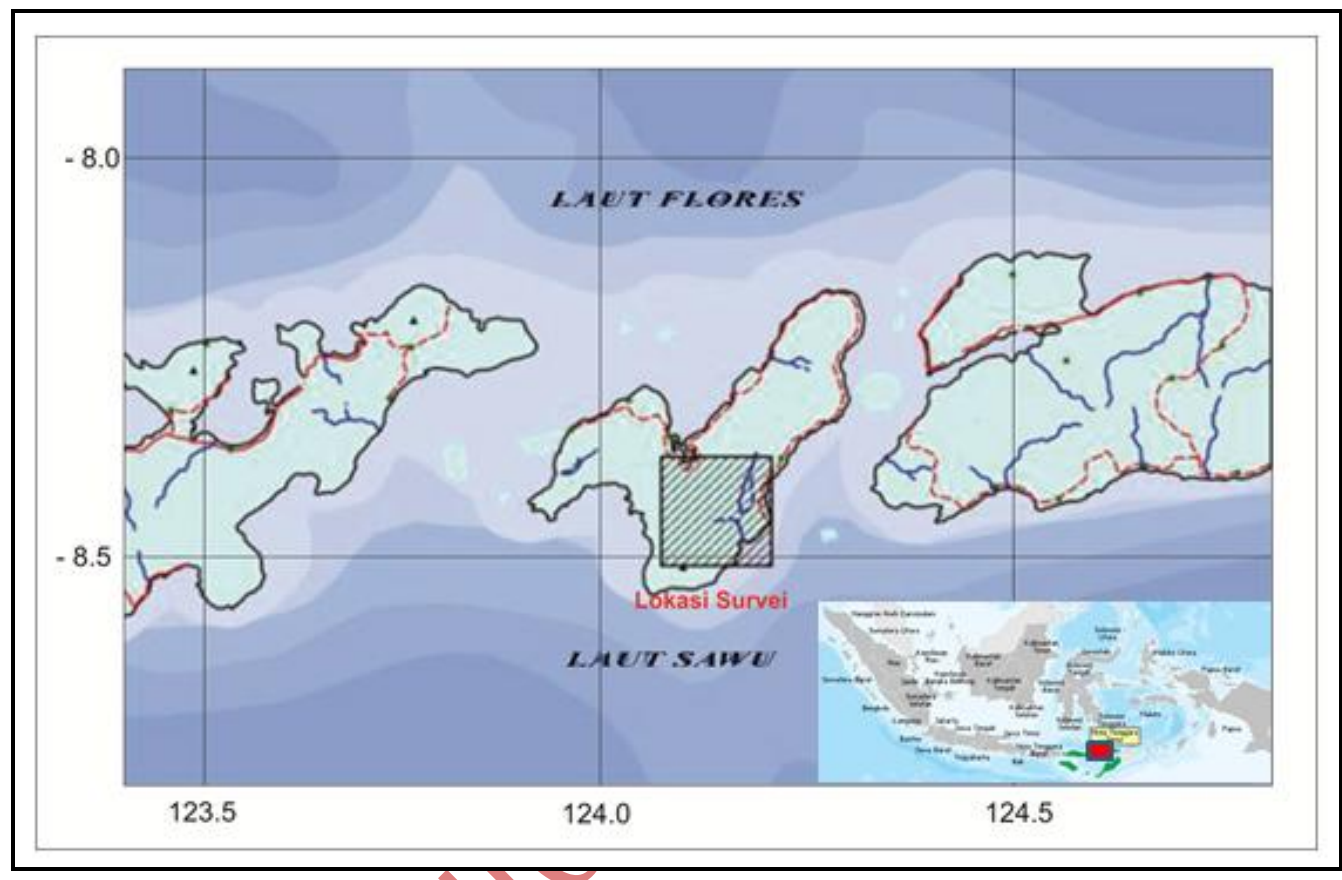

Fig 1 : Location Map

\section{METHOD}

This study using the Magnetotellurics (MT) method. This method is one of the passive geophysical exploration methods which aims to record the magnitude of the earth's electromagnetic field (EM), in order to determine subsurface conditions. The EM field is caused by various physical processes which are quite complex so that the frequency spectrum is very wide $\left(10^{-5} \mathrm{~Hz}-10^{4} \mathrm{~Hz}\right)(\mathrm{W}$. Lowrie, 2007). Variations in the range of audio frequencies (audio frequency band, between $1 \mathrm{~Hz}$ to $104 \mathrm{~Hz}$ are generally caused by meteorological activity in the form of lightning (W.D. Parkinson, 1983).

The phenomenon of electricity-magnetism affects the nature of electricity, especially the conductivity of the medium (earth) can be exploited for exploration purposes by using the MT method. This is done by simultaneously measuring variations in the electric field (E) and magnetic field (H) as a function of time.
Information about the conductivity or resistivity of the medium contained in the MT data can be obtained by means of the Maxwell equation using relatively simple models. At each MT measurement can produce apparent resistivity information as a function of frequency which can then produce true resistivity to depth (m).

MT is recording low frequencies (around $0.001-1 \mathrm{~Hz}$ ). Characteristics of the survey area are prominently depicted by 2D model, and 3D model have environment at deeper depth. (A. Sircar, 2017)

MT measurements in this area have scattered observation points so that they can be drawn into a 4lines west-east trending path. The results of the field data are then processed by the Fourier transform data to the $2 \mathrm{D}$ inversion process, then visualization of the 3D model to be analyzed into subsurface geological information. 
Volume 8 Issue 5 May 2020

\section{REGIONAL GEOLOGY}

The rocks that occupy the north and east coasts are sedimentary rocks, which are limestone reefs, in the middle there are the oldest rocks formed at the end of Tertiary namely Kongmewas rocks and Kalondama volcanic rocks with a geological structure directed north which separates the two old volcanic products. Volcanic products in the form of old Sirung products occupy the middle to the eastern part of Beang beach, while the Sirung pre-caldera formation is filled with Boyali volcanic products, and Mauta is in the south.

In the middle between the peaks of Sirung Tua and Boyali, a large explosion process occurs which produces pyroclastic and basal lava. The old Sirung pyroclastic product and the material that came out was the result of a large eruption which caused a mass vacuum in the middle to collapse and form the Sirung caldera. Volcanic activity appears next to the collapsed caldera wall forming Sirung's lava body and outside the caldera forms Beang Hill. The young Sirava lava in the middle of the Sirung crater is the youngest product of the Sirung complex. The geological structure that developed in the field of investigation is dominated by the north-south direction relatively as a major internal fault. This pattern is related to the regional tectonic direction that is developing in the Pantar area (Figure 2).

In this area there are volcanic structure patterns such as caldera, allegedly formed by a massive eruption that exploded from the eruption of the Mount Sirung Complex resulting in a mass vacuum and collapsed to form a caldera and a crater. The volcanic structure pattern of Sirung volcanic caldera formed around the summit of Mount Sirung forms linear with diameters starting from 2 km (M.N. Hadi, 2015).

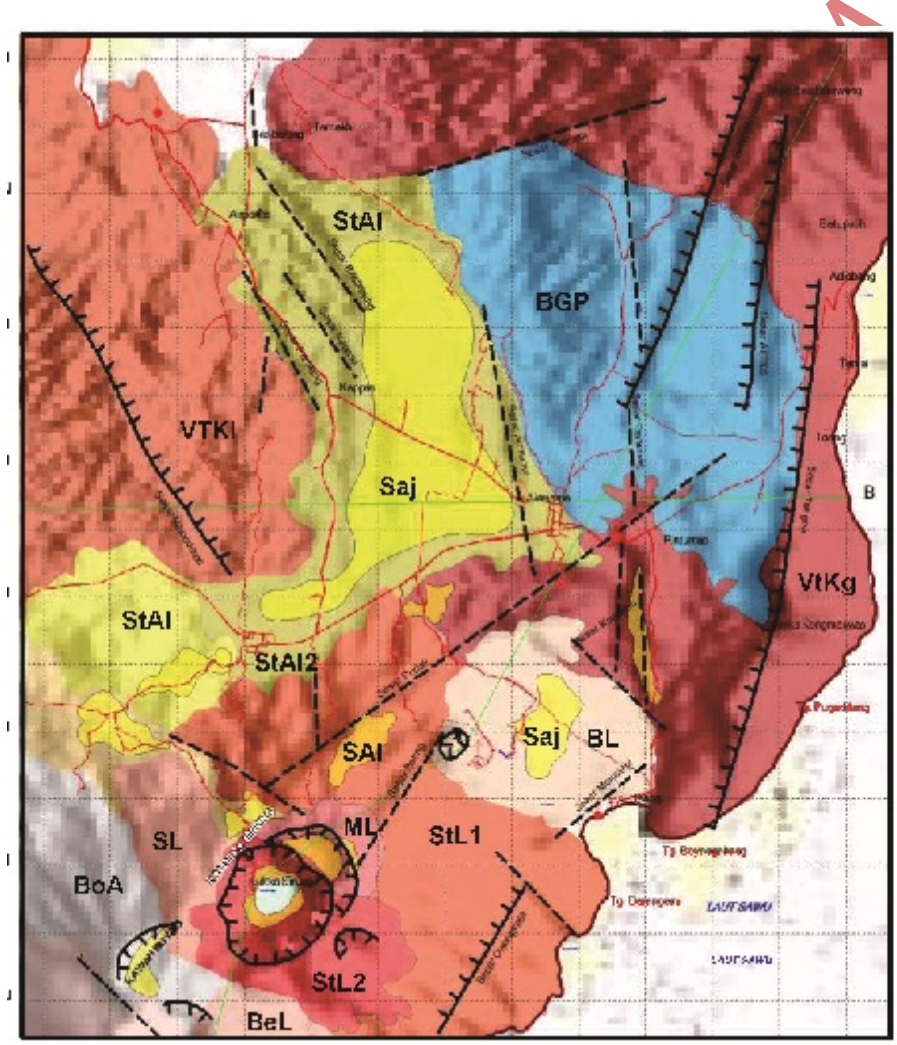

GEOLOGICAL MAP PANTAR, EAST NUSA TENGGARA INDONESIA

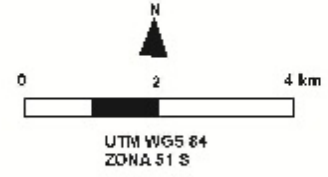

Note:

SL : Sirung Lava

ML : Mauta Lava

StL1 : Sirung Old Lava

BoA : Boyali Piroclastic

SAj : Sirung Piroclastic

BL : Boyali Lava

StAl : Sirung Old Piroclastic

BGP : Limestone

VtKg :Kongmawas Old Yulkanic

VTKI :Kalondama Old Vulkanic

BeL : Beang Lava

\section{INDEX MAP}

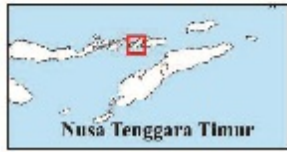

Fig 2 : Geological Map of Pantar Island, Indonesia

\section{RESULT}

The model results in the study area are designed to be representative of all regions that are thought to have geothermal prospects based on the results recommended by previous studies. Vertical models in the study area are displayed as many as 4 (four) lines trajectories representing the study area. The results of 
Volume 8 Issue 5 May 2020

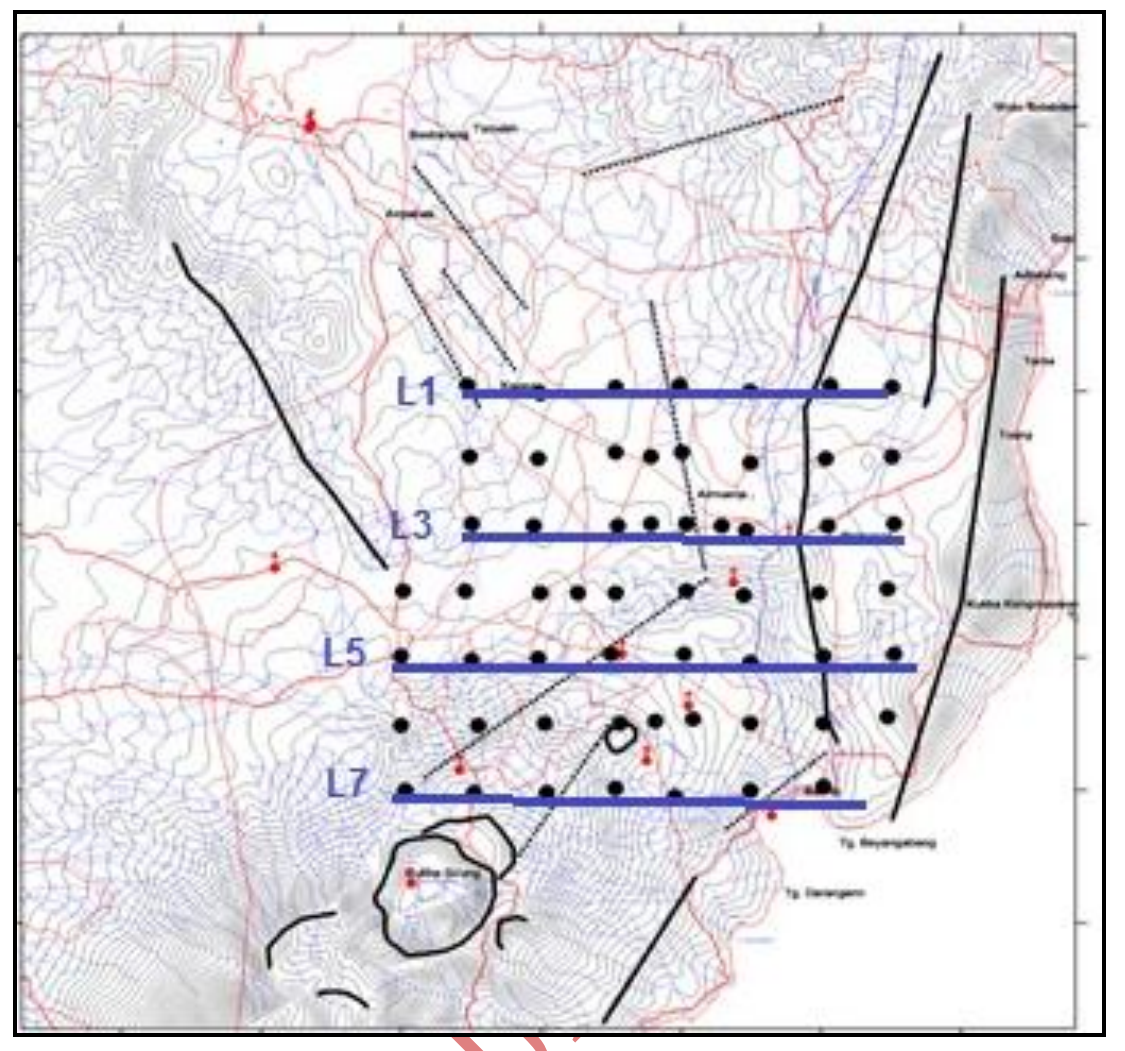

Fig 3 : Pantar Location Map with 4 lines MT

The results of this study obtain a subsurface model that is produced deeper than the previous resistivity method (K. Vozoff, 1991), thus providing heat source zone information on the geothermal system on Pantar Island. The resistivity distribution is displayed in various color scales. Blue indicates low resistivity (conductive), and red represents rocks with high resistivity values.

The zone of low value $\leq 20 \Omega \mathrm{m}$ from the surface to a depth of $-700 \mathrm{~m}$ and detected to a deeper depth that is a depth of $-1000 \mathrm{~m}$ at other locations, is generally spread over most of the investigation area. Low zone around the manifestation of geothermal is thought to be related to hydrothermal activity in the form of alteration rocks which are found around the emergence of hot and hot water, tuff, breccia, polymic breccia, and pyroclastic. The results of the study also carried out a structural interpretation of the results of $2 \mathrm{D}$ resistivity model from this MT data. The 2D model is displayed in a vertical cross section that describes the vertical resistivity distribution of rocks.(A. Singarimbun, 2017) $\underline{\text { Line } 1}$

Line 1 is in the northernmost position than the other lines, this track is east-west. The modelling results show rock resistivity values from $0 \Omega \mathrm{m}$ to $\geq 250 \Omega \mathrm{m}$.

Line 1 (Figure 4), the uppermost layer with a low resistivity value $(0-20 \Omega \mathrm{m})$ shown by the blue layer, this layer continues from the surface to a depth of $1100 \mathrm{~m}$ in the west and east of the track, while in the middle of the track has a depth of $-750 \mathrm{~m}$. The low resistivity zone on this path is thought to be the response of the hydrothermal activity product rock in the form of alteration rocks and volcanic sedimentary rocks, this zone is thought to be a clay cap in this geothermal system. (H. Weldeyohannes, 2018)

The green-yellow zone, has a resistivity value of 20$100 \Omega \mathrm{m}$, this zone starts to appear at a depth of $-750 \mathrm{~m}$ which is in the middle of this path, in the west starts from a depth of $-1000 \mathrm{~m}$, and the east of this layer starts at a depth $-1200 \mathrm{~m}$. This layer is thought to be a transition zone between alteration rock and reservoir. Rock layers with moderate resistivity values are found 
Volume 8 Issue 5 May 2020

along this path extending from west to east. Rock resistivity with a value of $20-100 \Omega \mathrm{m}$ starting from a depth of -1000 meters is thought to be a reservoir. This zone is thought to be the top of the reservoir of the Pantar Island geothermal system.

Rock resistivity zones with high values (> 250 $\Omega \mathrm{m}$ ) are shown by layers with a red-pink color starting to appear at depths approaching $-2000 \mathrm{~m}$. This high resistivity zone is thought to be a heat-bearing rock from the Pantar Island geothermal system.

\section{$\underline{\text { Line } 3}$}

In line 3 (Figure 5), the resistivity modeling results show the resistivity value of rocks from $0 \Omega \mathrm{m}$ to $\geq 250$ $\Omega \mathrm{m}$. At the very top there are rocks with low resistivity values $<20 \Omega \mathrm{m}$ spread from west to east starting from the surface to a depth of about $1000 \mathrm{~m}$. The rock zone with a low resistivity value is interpreted as a zone of change in the middle and sea water intrusion in the east. Underneath is a medium resistivity value interpreted as a reservoir of the Pantar geothermal system, this zone starts at a depth of $-1000 \mathrm{~m}$. Whereas for rocks with high resistivity values, it is suspected as a response from heat-carrying rocks. The location of the high resistivity is shifting increasingly to the center. Resistivity contrast as an illustration of the Pintumas fault is still visible in the east, this structure is a depiction of the puriali fault and the pintumas faut shown on the geological map (M.N. Hadi, 2015)

\section{$\underline{\text { Line } 5}$}

In this path (Figure 6) we still see low rock resistivity extending from west to east, where the low resistivity associated with alteration of hydrothermal activity is located in the middle which is indicated by the resistivity value of 0-20 $\Omega \mathrm{m}$ (blue) which is suspected as clay cap, this layer continues to a depth of $-1000 \mathrm{~m}$, while rocks with low resistivity in the east are thought to be still affected by sea water intrusion. The resistivity contrast which shows the picture of the Pintumas fault is more clearly visible and narrower than the previous path. On this path there is a moderate resistivity value on the surface that is thought to be associated with the pyroclastic flow of Mount Sirung, this area is indicated by the green scale in the cross section model. In the next layer there is a resistivity value of 20-100 $\Omega \mathrm{m}$ (green-yellow), rock layers with moderate resistivity values are found along this path extending from west to east. Rock resistivity with a value of 20-100 $\Omega \mathrm{m}$ starting from a depth of -1000 meters is thought to be a reservoir. This high resistivity anomaly $\geq 250 \Omega \mathrm{m}$ is associated with Mount Sirung's body which is thought to be a heat-bearing rock from the Pantar geothermal system.

\section{Line 7}

This track is at the southern end. The results (Figure 7) show a medium-high resistivity value (> $20 \Omega \mathrm{m})$ on the surface which is thought to be a response from volcanic rock units in the form of lava. Underneath is a low resistivity value $(<10 \Omega \mathrm{m})$ that extends from west to east. The low resistivity value in the west is thought to be the response of alteration rocks resulting from hydrothermal, tuff, breccia, polymic breccia, and pyroclastic. While the low resistivity value in the east is thought to be the influence of sea water intrusion.

The low resistivity value that is thought to be closely related to hydrothermal activity is in the middle of this passage and passes through several geothermal manifestations. The shape of the zone of low resistivity value in this section is assumed to be the closing zone of the geothermal system of the island of Pantar. After the low resistivity zone, there is a rock layer with a medium resistivity value (20-100 $\Omega \mathrm{m}$ ) from a depth of $-1000 \mathrm{~m}$ to $-2000 \mathrm{~m}$, which is assumed to be a reservoir in the form of a graben. To the east of this interesting zone there is a contrast value of resistivity, indicating the existence of a structure that is a barrier of the prospect zone of this area. This structure is a depiction of the puriali fault and the Pintumas fault shown on the geological map (M.N. Hadi, 2015)

\section{$\underline{\text { 3D model }}$}

The results from 3D model (Figure 10) show that the first layer of this area has rock resistivity with a resistivity value of $\leq 20 \Omega \mathrm{m}$ that occupies the entire investigation area at the surface to a depth of $-1000 \mathrm{~m}$. The low resistivity value in this area is thought to be the response of the alteration zone which is a product of hydrothermal activity and the response of tuff, breccia, polymic breccia, and pyroclastic breccia. It is suspected that this zone is a clay cap ( zone in the Pantar geothermal system.

At a depth of $-750 \mathrm{~m}$, a low-moderate resistivity value (20 - $50 \Omega \mathrm{m}$ ) is suspected. It is assumed that the lowmoderate restivity value is a response from the lava lithology that spreads almost in most areas of investigation. This low-moderate resistivity value is thought to be a transition zone between the alter rock and the reservoir. 
Volume 8 Issue 5 May 2020

At a depth of -1000 meters the resistivity zone is expanding and forming a closed closure covering almost all of the manifestations around Mount Sirung. This medium resistivity value at a depth of $-1000 \mathrm{~m}$ is thought to be the peak of the reservoir of the Pantar Island geothermal system.

At depths of more than -1000 meters the expansion of the resistivity value of $20-100 \Omega \mathrm{m}$ is seen, this shows that the geothermal system in Pantar is located along the emergence of geothermal manifestations starting from Mount Sirung to the northeast to the Airmama heat. The rock zone with a resistivity of 20-100 $\Omega \mathrm{m}$ at a depth of -1000 meters is thought to be a reservoir zone in the Pantar geothermal system. At depths of $1500 \mathrm{~m}$ the presence of rocks with moderate resistivity (20-100 $\Omega \mathrm{m}$ ) leads to groups of rocks with higher resistivity values $(>100 \Omega \mathrm{m})$.

In the east there is a low resistivity value, it is suspected that this is not related to hydrothermal activity, this low resistivity value is a response from limestone and also the response from sea water intrusion. This is due to its location in the eastern and southeastern regions directly adjacent to the sea.

At depths of $-2000 \mathrm{~m}$, visible rocks with a high resistivity value $>200 \Omega \mathrm{m}$ are located just below the medium resistivity value at the previous depth. This high resistivity value is thought to be the heat-bearing rock (heat source) of the Pantar Island geothermal system. (T. Rahadinata, 2015).

\section{CONCLUSION}

The subsurface geology of the Pantar geothermal system includes clay cap zones with resistivity values $<20 \Omega \mathrm{m}$ in some areas to a depth of $-1000 \mathrm{~m}$ which are thought to be alteration, tuff, breccia, polymic breccia, and pyroclastic. After the clay cap zone, there is a rock zone with a resistivity of 20-100 $\Omega \mathrm{m}$ which is suspected as a reservoir zone, this layer is at a depth of $-1000 \mathrm{~m}$ and in some areas began to appear at a depth of $-750 \mathrm{~m}$. At depths starting from -2000 meters showing a high resistivity value $>200 \Omega \mathrm{m}$ is thought to be a heat-bearing rock from the Pantar Island geothermal system, at a depth of -3000 meters this zone is expanding.

\section{ACKNOWLEDGMENTS}

The authors thank the research team of the Centre for Coal, Minerals, and Geothermal Resources, the geothermal field group, for helping and authoring the writing of this paper.

\section{REFERENCES}

[1]. D.H. Carlson, \& C.C. Plumer, "Physical Geology", $16^{\text {th }}$ Edition, Mc Graw Hill. New York, 2019.

[2]. I.S.Moeck. "Catalog of geothermal play types based on geologic controls", Renewable and Sustainable Energy Reviews (37) 867-882. 2014.

[3]. T. Rahadinata, I. Taqodama., "Gravity and audiomagnetotelluric (AMT) survey, Pantar Geothermal Area, East Nusa Tenggara”. PSDG. Bandung. Indonesia. (Text in Indonesian), 2015.

[4]. S. Panjaitan, "Geology of Ulubelu Tanggamus geothermal area, North Lampung Based on Magnetotelluric (MT) Method Analysis". Jurnal Geologi dan Sumberdaya Mineral, Vol. 20, No. 2 Badan Geologi. Indonesia. (Text in Indonesian), 2010, pp. 69-91

[5]. W. Lowrie, "Fundamentals of Geophysics" second edition, Cambridge University Press, United Kingdom, 2007.

[6]. W.D. Parkinson, "Introduction to Geomagnetism", Scotish Academic Press. 1983, pp. 220-346.

[7]. A. Sircar, S. Dhale, M. Shah, D. Vaidya, K. Yadav, "2D and 3D Magnetotelluric survey for geothermal reservoir identification". Drilling and Exploration World (DEW) Journal, Dehradun, India, June 2017, pp.61-75.

[8]. M.N. Hadi, D. Kusnadi, "Geological and geochemical survey, Pantar Geothermal Area, East Nusa Tenggara”. PSDG. Bandung. Indonesia. (Text in Indonesian)

[9]. K. Vozoff, "The Magnetotelluric Method" in Nabighian, Electromagnetic method in Applied Geophysics, vol. II, part B: Society of Exploration Geophysicists, Tulsa Oklahoma, 1991, pp. 641711.

[10]. A. Singarimbun, E. Z. Gaffar, P. Tofani, "Modeling of reservoir structure by using magnetotelluric method in the area of Mt. Argopuro, East Java, Indonesia”. J. Eng. Technol. Sci., Vol. 49, No. 6, December 2017, pp. 833-847,

[11]. H. Weldeyohannes, "Magnetotelluric methods in geothermal exploration at Aluto Langano Ethiopia". Proceedings, $7^{\text {th }}$ African Rift Geothermal Conference Kigali, Rwanda. 2018. 
ijournals: International Journal of Software \& Hardware Research in Engineering

ISSN-2347-9698

Volume 8 Issue 5 May 2020

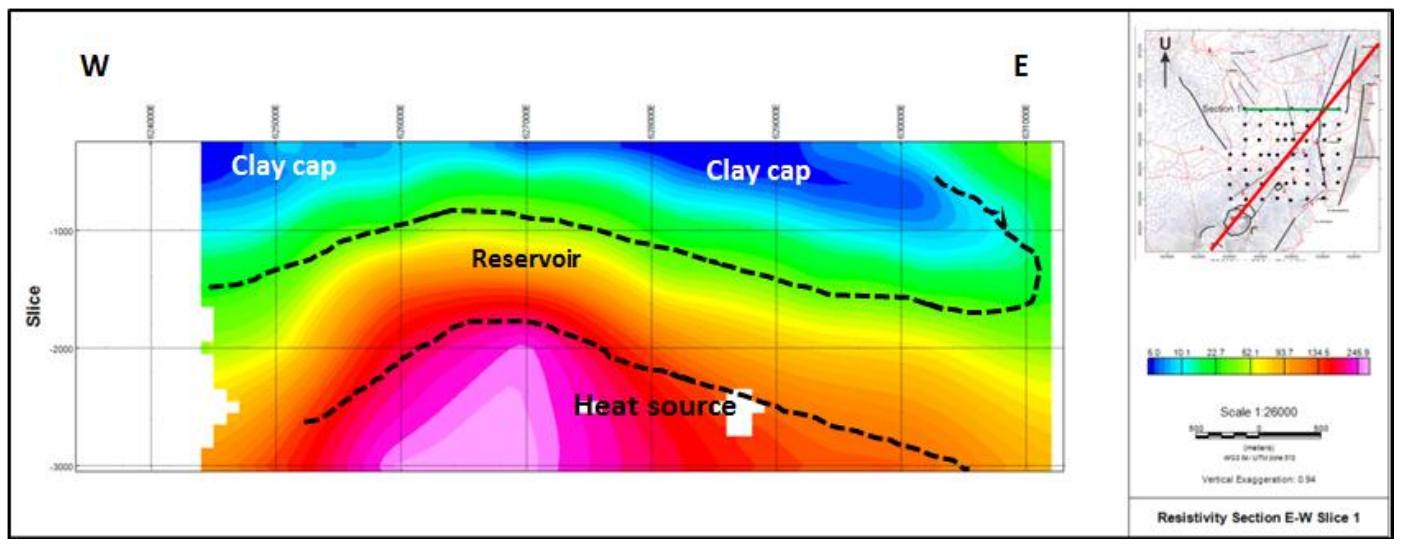

Fig 4 : 2D Model of Line 1

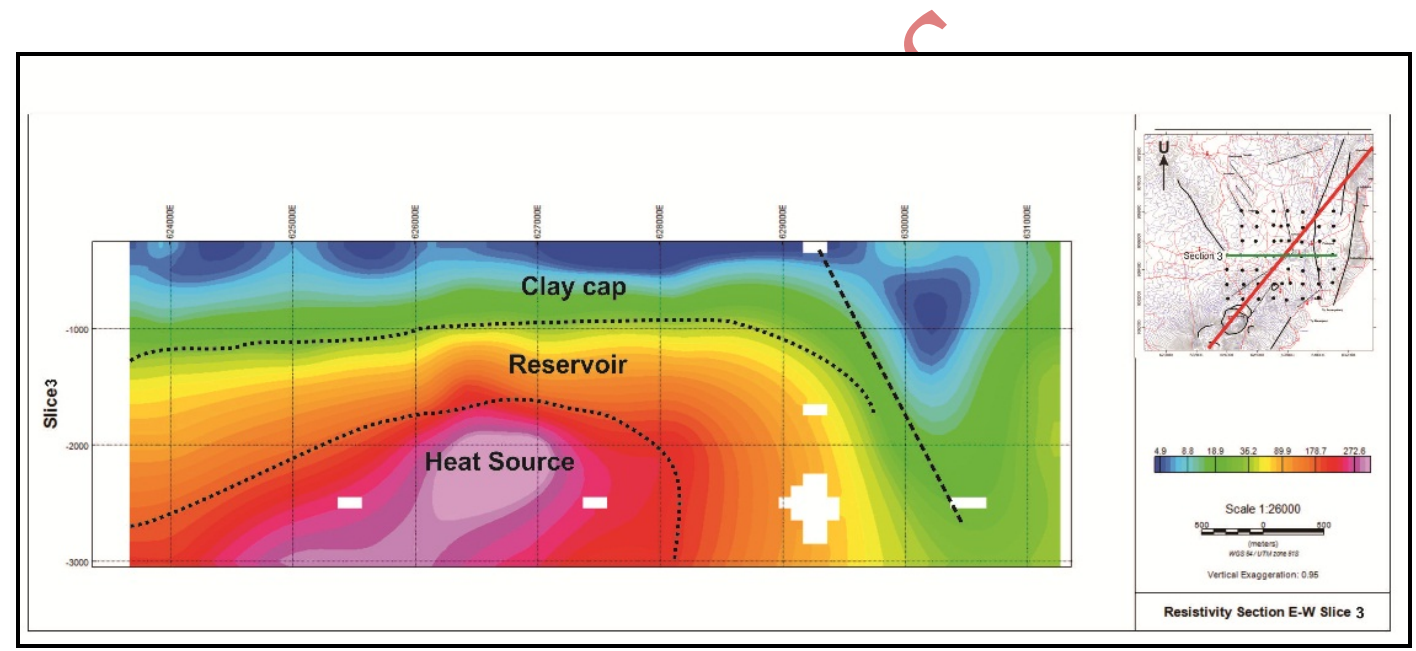

Fig 5 : 2D Model of Line 3

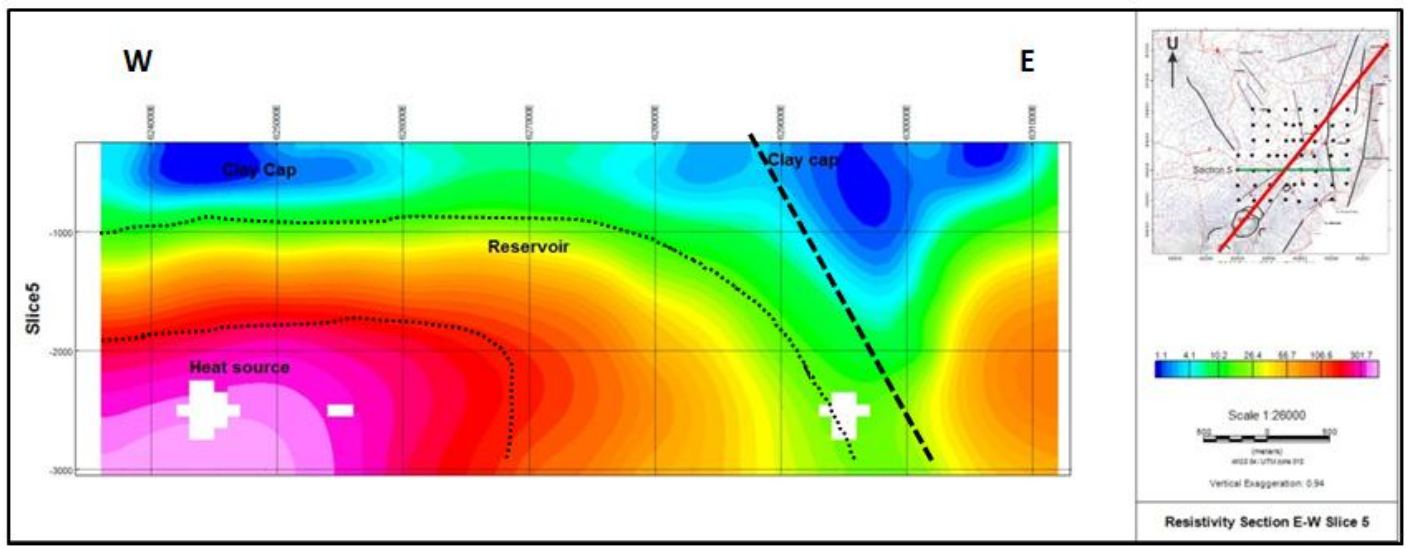

Fig 6 : 2D Model of Line 5 
ijournals: International Journal of Software \& Hardware Research in Engineering ISSN-2347-9698

Volume 8 Issue 5 May 2020

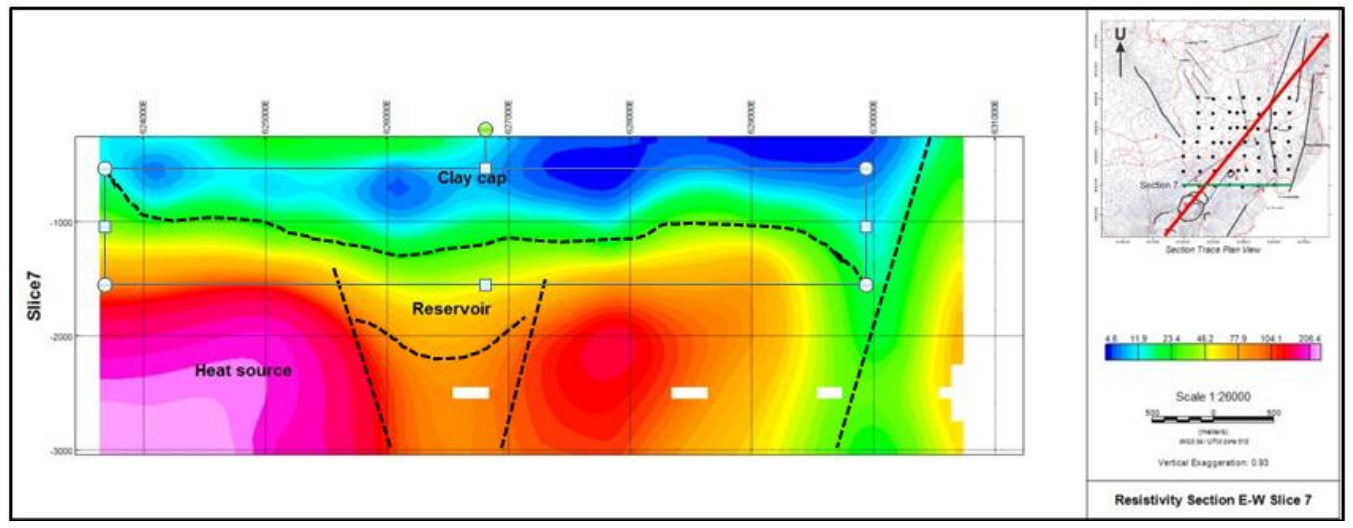

Fig 7 : 2D Model of Line 7

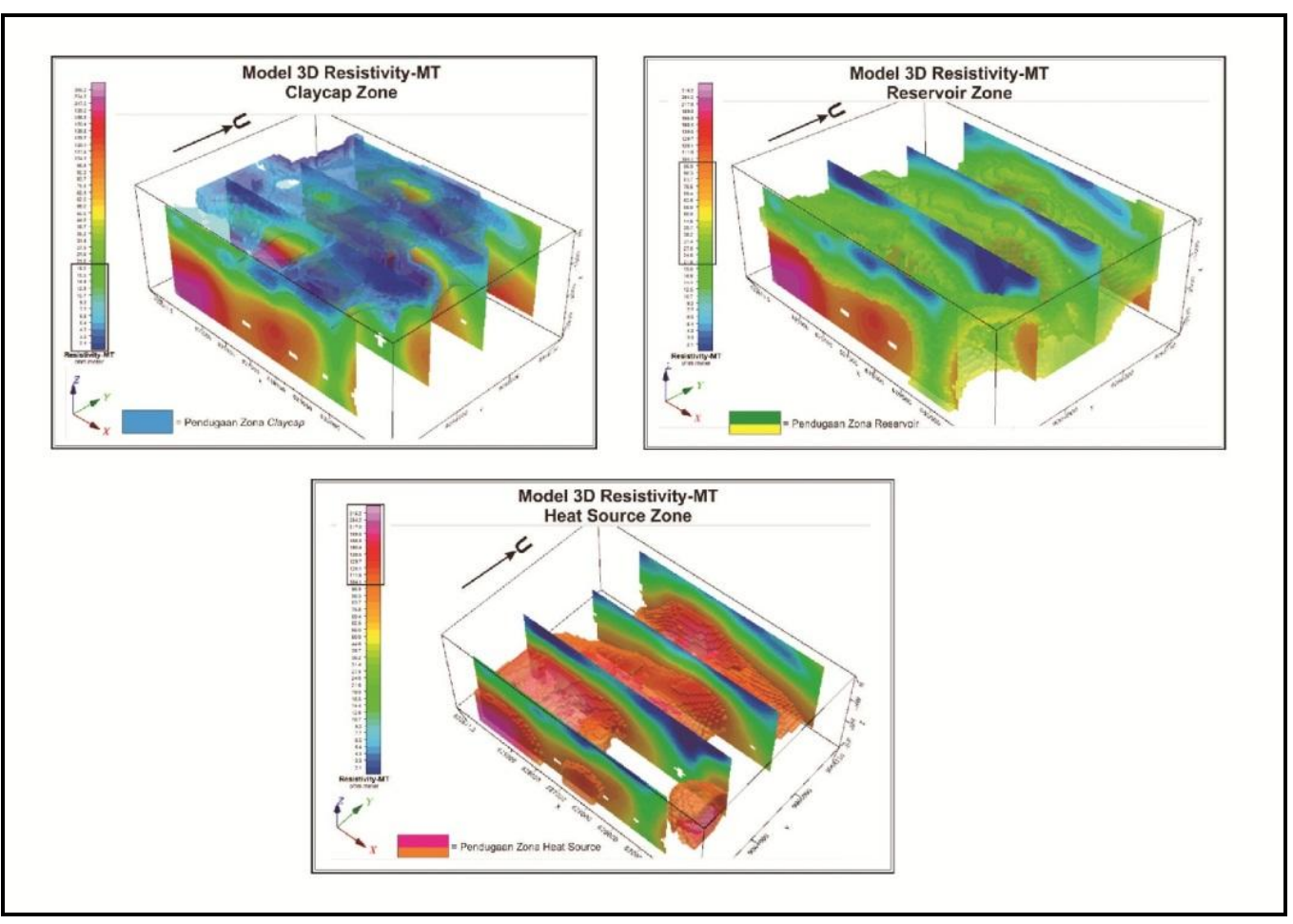

Fig 8 : 3D Geothermal Zone Based on Resistivity Model 
ijournals: International Journal of Software \& Hardware Research in Engineering

ISSN-2347-9698

Volume 8 Issue 5 May 2020

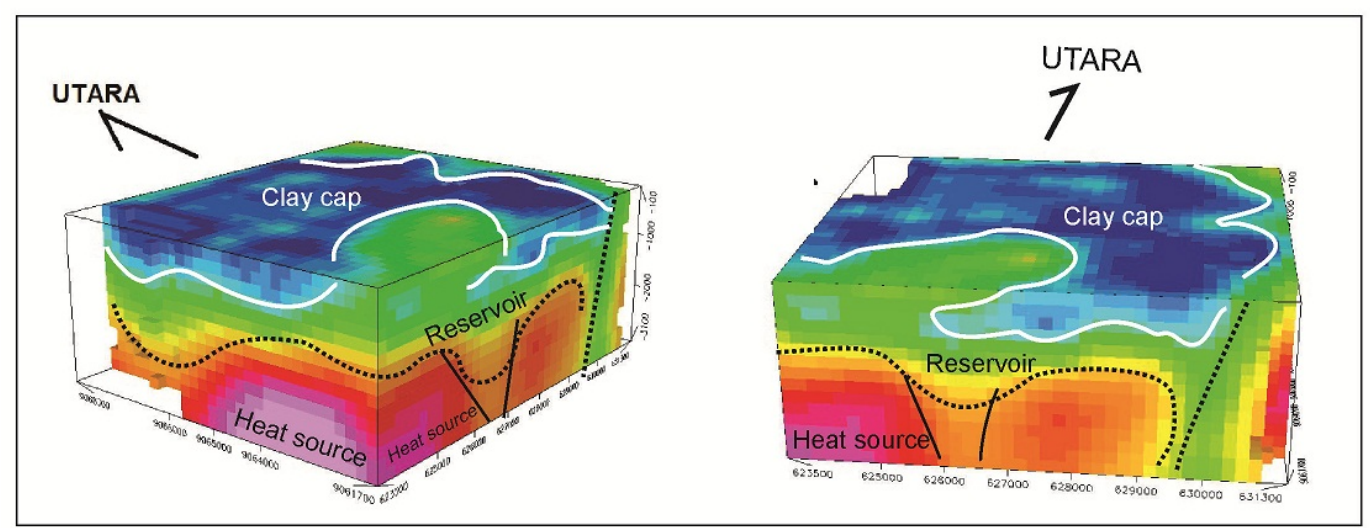

Fig 9 : 3D Resistivity Model and Interpretation

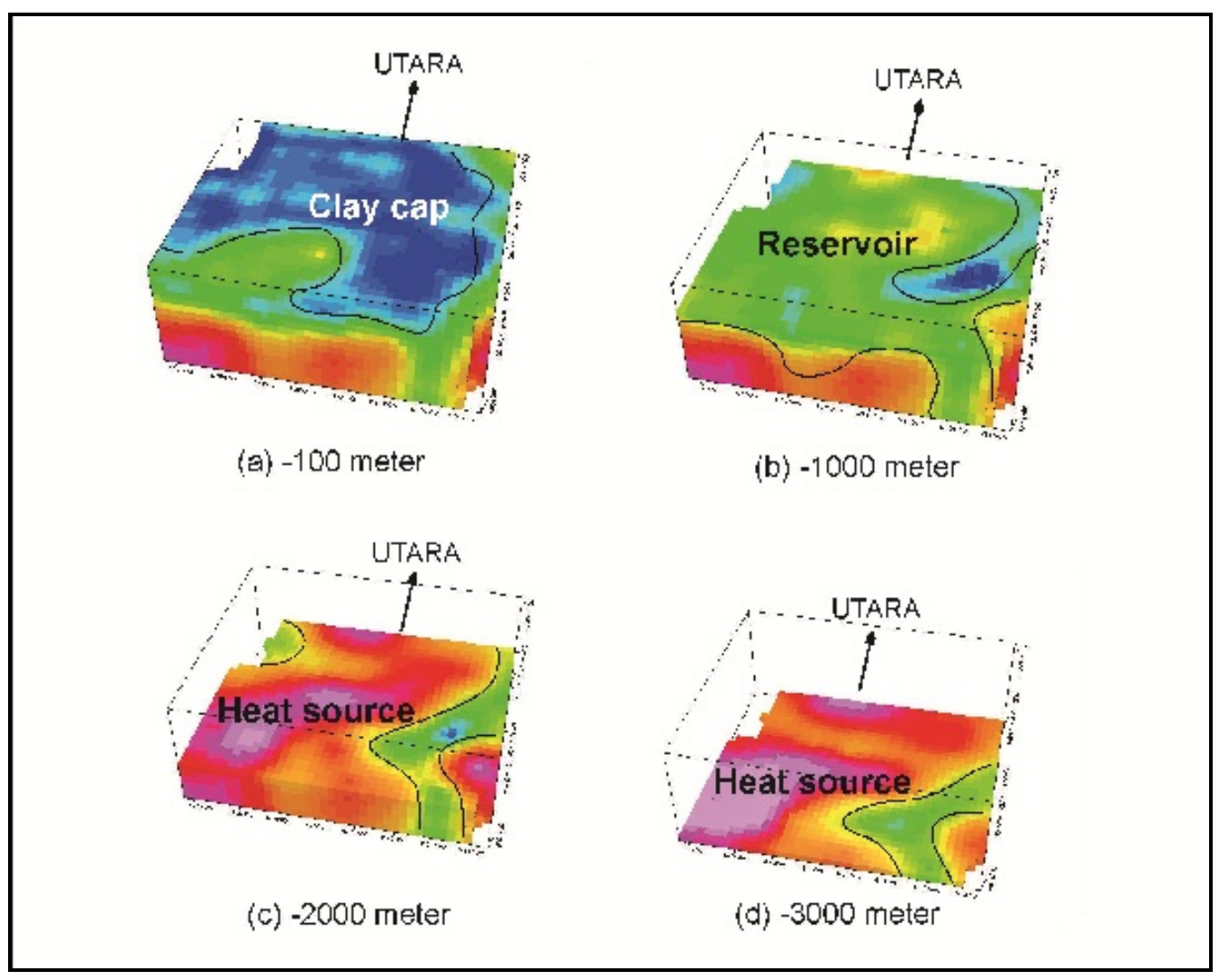

Fig 10 : 3D Resistivity Model for Depth Map 